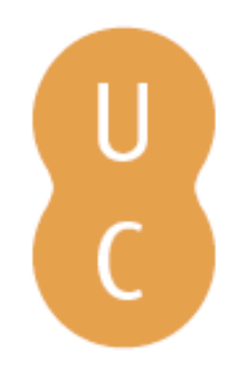

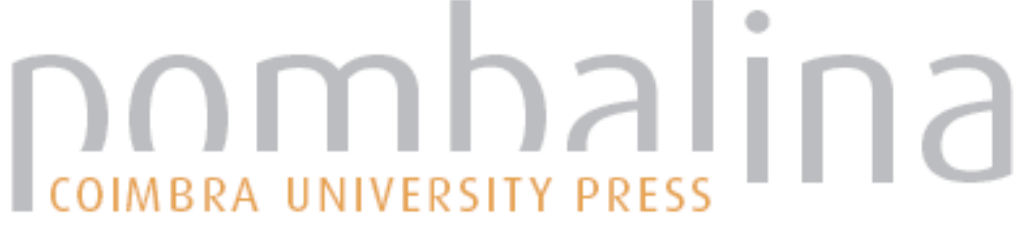

\section{Feminismo e pós-modernidade: figuras e controvérsias}

\author{
Autor(es): Henriques, Fernanda
}

Publicado por: Imprensa da Universidade de Coimbra

URL

persistente: $\quad$ URI:http://hdl.handle.net/10316.2/42348

DOI: $\quad$ DOI:https://doi.org./10.14195/978-989-26-1308-6_36

Accessed : $\quad$ 26-Apr-2023 10:30:28

A navegação consulta e descarregamento dos títulos inseridos nas Bibliotecas Digitais UC Digitalis, UC Pombalina e UC Impactum, pressupõem a aceitação plena e sem reservas dos Termos e Condições de Uso destas Bibliotecas Digitais, disponíveis em https://digitalis.uc.pt/pt-pt/termos.

Conforme exposto nos referidos Termos e Condições de Uso, o descarregamento de títulos de acesso restrito requer uma licença válida de autorização devendo o utilizador aceder ao(s) documento(s) a partir de um endereço de IP da instituição detentora da supramencionada licença.

Ao utilizador é apenas permitido o descarregamento para uso pessoal, pelo que o emprego do(s) título(s) descarregado(s) para outro fim, designadamente comercial, carece de autorização do respetivo autor ou editor da obra.

Na medida em que todas as obras da UC Digitalis se encontram protegidas pelo Código do Direito de Autor e Direitos Conexos e demais legislação aplicável, toda a cópia, parcial ou total, deste documento, nos casos em que é legalmente admitida, deverá conter ou fazer-se acompanhar por este aviso.

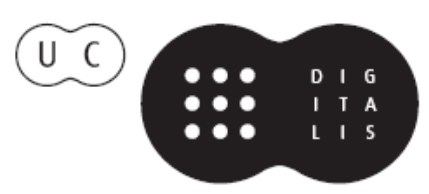





\section{FEM I N I M O E PÓ S-MODER N I A D E FI G URAS E CONTROVÉRSIAS}

Resumo: Neste texto procura-se articular dois conceitos em si mesmos problemáticos: o de feminismo e o de pós-modernidade. Embora se faça referência a textos/posições clássicas sobre o tema, o objetivo deste ensaio não é fazer uma revisão de literatura, mas, sim, pensar o sentido da articulação entre feminismo e pós-modernidade, realçando os aspetos controversos que tal articulação levanta.

Palavras-chave: feminismo; modernidade; pós-modernidade; racionalidade; paradigma epistemológico.

Abstract: This text seeks to articulate two concepts in themselves problematic: feminism and post-modernity. Although references are made to texts and classic positions on the subject, the purpose of this essay is not to do a literature review, but instead to think about the meaning of the relationship between feminism and postmodernism, highlighting the controversial aspects involved in such a relationship.

Keywords: feminism; modernity; post-modernity; rationality; epistemological paradigm. 


\section{Sentido e implicações de um título}

O título deste trabalho é constituído por duas palavras, feminismo e pós-modernidade, que remetem para dois conceitos estruturalmente polémicos. Por isso, o seu subtítulo é "figuras e controvérsias". Na verdade, considero que sobre o tema não poderemos ultrapassar a apresentação de perspetivas e a sua discussão e nunca elaborar uma relação líquida e pacífica, até porque ambas as palavras/conceitos se têm de conjugar no plural para poderem descrever as realidades que pretendem referenciar. É igualmente impróprio falar de "feminismo" como o é falar de "pós-modernidade", porque feminismo não consegue descrever as posições, por exemplo, de Simone de Beauvoir ou de Judith Butler, embora sejam ambas feministas, assim como Gianni Vattimo ou Fredric Jameson oferecem duas conceções bem diferentes do que pode ser a perspetiva da pós-modernidade - o primeiro apontando, sobretudo, para a dimensão de fragilidade da razão, para a ideia de um pensamento débil; o segundo articulando a cultura pós-moderna com o desenvolvimento do capitalismo, definindo-a como a expressão do capitalismo tardio ${ }^{1}$. Quer isto dizer que escrever sobre feminismo e pós-modernidade exige um percurso analítico que percorra alguns caminhos que as palavras/ conceitos têm desenhado.

Mas, no título, as duas palavras/conceitos estão ligadas pela partícula "e" que, em função da sua pertença gramatical, simultaneamente une e contrasta, apontando quer para o sentido, quer para o sem sentido da relação entre elas. Isto é, feminismo e pós-modernidade são com-possíveis ou im-possíveis? É a interrogação que subjaz ao

${ }^{1} \mathrm{Na}$ verdade, o debate sobre a pós-modernidade tem uma literatura quase inabarcável. Indico aqui os autores (os textos estão na bibliografia) que participam mais ativamente na minha interpretação do tema: Lyotard, Perry Anderson, Matei Calinescu, Gianni Vattimo, Zygmunt Bauman, Habermas, David Harvey, além da coleção de ensaios organizada por Steven Connor. 
título proposto, sendo a sua análise que se pretende trazer à luz e, também a este nível, haverá que desocultar "figuras e controvérsias", na medida em que as posições e os argumentos se opõem e digladiam, esgrimindo, cada posição, razões igualmente fortes.

É esta interrogação subterrânea ao título que estruturará o desenvolvimento do texto e se constituirá como o seu horizonte de sentido.

\section{Uma RELAÇÃo controversa}

\subsection{Uma relação impossível}

Tendo em vista o que acabou de ser dito, que se procura indagar se há uma relação possível ou impossível entre feminismo e pósmodernidade, iniciarei a análise pela apresentação de algumas posições que consideram que feminismo e pós-modernidade têm uma relação impossível. Tal é o caso de uma grande parte das filósofas feministas espanholas, para quem é absolutamente claro que, tendo nascido com a sociedade moderna dos direitos e das reivindicações, o feminismo não é compossível com a racionalidade pós-moderna. Esta é a posição de Celia Amorós, figura matricial da filosofia de raiz feminista em Espanha que, em 1987/88, criou, na Universidade Complutense de Madrid, o Seminário Feminismo y Ilustración, onde se desenvolveram as atividades de investigação ligadas a um conjunto de nomes que marcaram a investigação filosófica de cariz feminista em Espanha, e que manteve uma ligação ao grupo fundador do Instituto de Investigações Feministas, cuja atividade se destacou em 1989, nas comemorações do bicentenário da Revolução Francesa ${ }^{2}$. Para Celia Amorós, apenas se pode falar de feminismo a partir da

2 Cf. Revista Isegoría 38 (2008): 197-203. 
modernidade, porque só a racionalidade moderna oferece um estatuto racional que permite o percurso compreensivo e emancipador das mulheres. Amorós reitera, de modo sistemático, esta posição em todas as suas obras, porque, para ela, a pós-modernidade representa um registo de morte, designadamente de morte do sujeito racional capaz de tematizar a sua própria posição e estatuto e de ser seu protagonista:

Pós-modernidade. Diagnóstico em que se plasma ainda às apalpadelas e tenta articular-se, como afirma Wellmer, a consciência de uma nova época, a nossa. E cuja caracterização sumária. . . se concretiza, como é sabido, em torno de determinados registos de morte: morte do sujeito, morte da razão, morte da história, morte da metafísica, morte da totalidade. Morte de toda uma rede de categorias e conceitos, cujas relações orgânicas vertebravam o projeto da modernidade, o projeto ilustrado entendido como a emancipação do sujeito racional, sujeito que, de algum modo, se encontrava em posição constituinte em relação ao projeto histórico interpretado a partir de alguma ou algumas chaves totalizadoras relacionadas, por sua vez, com o protagonismo desse sujeito e com os avatares da sua sujeição ou da sua libertação. (320)

No âmbito desta mesma "Escola", Cristina Molina Petit (129-143) ${ }^{3}$ questiona fortemente o interesse para o feminismo daquilo que se poderá designar por imagem feminina da racionalidade pós-moderna. A autora trata sobretudo duas metáforas - a da razão piedosa, ligada a Vattimo e a da razão estetizada que articula com o que chama pensamento do corpo - denunciando que estas perspetivas sobre a

3 Ver também: Cristina Molina Petit, Dialéctica feminista de la ilustración (Barcelona: Anthropos, 1994), onde a autora articula aquilo que é o lugar próprio do feminismo - o século das luzes. 
racionalidade, embora feminizadas - ou talvez por isso - não contribuem para uma melhor compreensão das problemáticas ligadas às mulheres, podendo mesmo constituir um forte obstáculo a essa compreensão. A justificação desta posição decorre de se considerar que uma razão enfraquecida não pode ser um instrumento emancipador como as posições feministas necessitam.

Num outro horizonte cultural, penso ser possível dizer que Elisabeth Badinter perfilhará a mesma posição da "Escola" espanhola de Celia Amorós (cf. Henriques 245-254). Tendo uma formação filosófica de base, contudo, as suas obras materializam um discurso de fronteira, de raiz interdisciplinar, onde a preocupação pela compreensão e pela busca do conceito ou do universal são a intencionalidade constitutiva. Articulando os dados da História, da Psicologia, da Biologia ou da Literatura, ela procura sempre a construção de uma visão sistemática que vá tão longe quanto possível na apresentação de uma totalidade orgânica de sentido. Em confronto com Alain Touraine, Badinter assume-se como herdeira de Beauvoir. Pertencendo a um feminismo da igualdade, defende o republicanismo como lugar social e político da liberdade e reivindica que a maior conquista da cidadania democrática corresponde ao "direito à indiferença" e não ao "direito à diferença". Ao longo do confronto com Touraine, fica muito clara a pertença de Badinter ao quadro racional da modernidade, com a consequente defesa do valor da universalidade da razão como instrumento de emancipação ${ }^{4}$.

\subsection{Uma relação necessária e fecunda}

No campo da língua inglesa, dois nomes importantes, Nancy Fraser e Linda Nicholson, advogam uma outra posição, salientando

${ }^{4}$ Cf. Le Nouvel Observateur de 19 de Junho de 2003. 
que da articulação entre feminismo e pós-modernidade poderão advir vantagens para ambas as perspetivas. Num texto sobre esta temática (1992), as autoras fazem a articulação entre feminismo e pós-modernidade procurando estabelecer uma complementaridade benéfica para os dois lados, porque, vindo de posições e interesses teóricos diferenciados, feminismo e pós-modernidade estabelecem críticas diferentes ao legado moderno, mas, exatamente, por isso mesmo, qualquer das críticas é parcelar e, portanto, incompleta, tendo toda a vantagem em se articular com a outra.

Para a questão da pós-modernidade, partem do clássico de Jean-François Lyotard, La condition postmoderne, sublinhando, na posição daquele autor, as duas ideias fundamentais da sua perspetiva: a morte do fundacionalismo e a consequente desvalorização do papel da filosofia. Na verdade é disso que se trata em Lyotard: mostrar que a filosofia tradicional, com o seu arsenal de "princípios primeiros", "transcendentalismos", "pureza racional" e "universalismo abstracto", arsenal esse suportado por um conceito de razão iluminista toda poderosa, não era compatível com a dinâmica científica e societal do século XX. Nesse sentido, há uma desvalorização do papel tradicional da filosofia que se outorgava a si mesma ser, de direito, o lugar principial de qualquer outra discursividade. Para Lyotard, a pós-modernidade corresponde ao fim do tipo de discurso que designa como meta narrativas ou narrativas legitimadoras que, a seu ver, perderam a credibilidade. No seu lugar coloca as pequenas narrativas, a pluralidade discursiva e a contextualidade.

$\mathrm{Na}$ análise de Lyotard, Fraser e Nicholson aclamam a destronização do papel tradicional da filosofia, enquanto "meta" de qualquer outra narrativa, mas recusam a consistência total da crítica de Lyotard e denunciam a sua fragilidade enquanto instrumento de crítica social. Nesse contexto, vão procurar, do lado dos feminismos, aquilo que possa fortalecer a visão pós-moderna configurada por Lyotard. 
Acentuando que o feminismo, partindo das necessidades da sua prática política, também recusa o papel da filosofia tradicional, Fraser e Nicholson argumentam que, nem sempre as perspetivas feministas têm sido coerentes com o seu princípio desconstrutor da filosofia tradicional, continuando a defender posições que são devedoras desses "velhos" pontos de vista filosóficos. É por quererem encontrar uma dimensão universal ou, pelo menos, transcultural, para explicar a exploração das mulheres que as feministas acabam por cair na armadilha das soluções tradicionais. Recorrendo aos exemplos de Schulamith Firestone, Gayle Rubin, o movimento Woman, Culture and Society, Chodorow, as autoras mostram como elas, ao quererem construir uma grande teoria social que unificasse a explicação da opressão das mulheres nas diferentes latitudes culturais, cada uma à sua maneira, constroem "quase" meta narrativas. De qualquer modo, dizem, elaboram explicações essencialistas e mono causais, e, por isso, devedoras de uma perspetiva filosófica tradicional ${ }^{5}$, cujo modelo de racionalidade, de facto, nunca serviu a causa feminista. Por outro lado, aliás, as novas vagas de feminismo batalham por fragmentar as posições globalizantes e totalizadoras, e procuram abrir caminho para a marcação das diferenças constituintes do tecido da realidade.

É no quadro desta dupla análise que Fraser e Nicholson proporão a ideia de um "feminismo pós-moderno" que, por um lado, tem de manter as narrativas históricas - que lhe permitirão compreender as raízes do sexismo -, e as macro estruturas sociais - para poder analisar problemas políticos gerais -, como queria Lyotard, mas, por outro, deverá seguir as diretrizes da perspetiva pós-moderna e portanto: (1) ser "não-universalista" e, antes, ater-se às mudanças culturais e históricas e não pretender estabelecer leis explicativas

5 Até mesmo a proposta de Carol Gilligan é analisada pelas autoras como pecando por facilitar um olhar dicotómico e, portanto, essencialista. 
universais; (2) abandonar a ideia de "um sujeito da história", não considerando conceitos unitários, como o de mulher ou de identidade de género e procurando integrar perspectivas plurais de análise, como classe, etnicidade, orientação sexual, por exemplo; (3) ser "pragmático", desenvolvendo uma política de alianças e metodologicamente plural em função das temáticas em causa.

\subsection{Uma relação entre quê?}

A relação entre feminismo e pós-modernidade que mais dá que pensar é, no meu entender, a de Judith Butler porque, coerente com o seu olhar estruturalmente desconstrutor, ela não assume a estabilidade de nenhum dos conceitos - feminismo ou pós-modernidade - e, por isso, não pode pensar a sua relação. É, sobretudo, a designação "pós-modernismo" que Butler desconstrói, chamando a atenção para slogans que habitualmente são ligados àquela designação e que, enquanto generalidades, demonstram não só desconhecimento da complexidade das posições que querem caracterizar, como também constituem um obstáculo à sua efetiva compreensão, Nesse sentido, diz, o que importa é questionar a própria designação:

Proponho que a questão do pós-modernismo seja lida não apenas como a questão que o pós-modernismo coloca para o feminismo, mas como a questão, o que é pós-modernismo? Que tipo de existência ele tem? Jean-François Lyotard defende o termo, mas ele não pode ser visto como exemplo daquilo que está fazendo todo o resto dos que passam por pós-modernistas. A obra de Lyotard está, por exemplo, em conflito com a de Derrida, que não sustenta a noção do "pós-moderno", e com a de outros autores dos quais querem que ele seja representante. É ele paradigmático? Têm todas essas teorias a mesma estrutura (uma noção confortadora para 
o crítico que quer dispensá-las todas de uma vez)? O esforço para colonizar e domesticar essas teorias sob uma única rubrica é uma simples recusa de conceder a especificidade dessas posições, uma desculpa para não ler, e não ler atentamente? (14)

É particularmente significativa a sua interrogação sobre a possível dimensão paradigmática de Lyotard, ponto de partida da posição defendida por Fraser e Nicholson, nomeadamente por denunciar que a eleição de paradigmas exemplificadores é "uma noção confortadora para o crítico que quer dispensá-las todas de uma vez". Evidentemente que a não fixação de um conceito ou de uma perspetiva pode paralisar qualquer análise e inibir a ação - neste caso, teórica - mas não deixa de ser muito importante esta denúncia de se tomar a parte pelo todo e de se simplificarem as questões retirandolhes a sua constitutiva aporeticidade. Butler quer evidenciar o facto de que qualquer redução totalizadora é manifestação de um poder, de uma perspetiva de dominação, que, no fundo, quer acabar com a complexidade e dissolver as questões.

Que propõe, então, Butler?

Antes de tudo, diria, a sua vontade é de manter sempre ativa a estrutura questionante da racionalidade e não a sua dimensão sintética. Isto significa a manutenção do caráter constitutivamente provisório de toda a argumentação, por um lado, e, por outro, a recusa de uma qualquer perspetiva universal. Afirmar um universal é sempre excludente não só porque desenha um todo que não contém todas as partes, mas, igualmente, porque o afirma como modelo e, portanto, define uma hierarquia. Penso poder ilustrar o que afirmei acima de Butler com recurso às suas palavras:

Não sei o que é pós-modernismo, mas tenho alguma idéia de que possa significar submeter noções do corpo e da materialidade a uma crítica desconstrutiva. Desconstruir o conceito de 
matéria ou de corpo não é negar ou recusar ambos os termos. Significa continuar a usá-los, repeti-los, repeti-los subversivamente, e deslocá-los dos contextos nos quais foram dispostos como instrumentos do poder opressor. Aqui é necessário obviamente declarar que as opções para a teoria não se exaurem presumindo materialidade, de um lado, e negando materialidade, de outro. É meu propósito exatamente não fazer essas duas coisas. Pôr um pressuposto em questão não é a mesma coisa que o suprimir; antes, é libertá-lo de sua morada metafísica a fim de ocupar e servir objetivos políticos muito diferentes. Problematizar a matéria dos corpos acarreta, em primeiro lugar, uma perda de certeza epistemológica, mas essa perda de certeza não tem por resultado necessário o niilismo político.

Se uma desconstrução da materialidade dos corpos suspende e problematiza o referente ontológico tradicional do termo, ela não congela, bane, torna inútil ou esvazia de sentido seu uso; ao contrário, proporciona as condições para mobilizar o significante a serviço de uma produção alternativa. (25-26)

\section{Do que está em causa}

Das três posições sumariadas acima, importa-me isolar o que para mim está em causa e que enunciaria como sendo a configuração de uma epistemologia da racionalidade não discriminadora ou não excludente.

Nesse quadro, compreendo a posição das feministas que recusam a perspetiva pós-moderna sobre a razão e a discursividade, embora não consiga aderir totalmente a ela por pensar que a crítica a que alguma pós-modernidade submeteu o conceito de razão da modernidade pode permitir reconfigurar uma racionalidade que, sendo, embora, mais frágil é, ao mesmo tempo, mais aberta e inclusiva, 
o que pode constituir uma nova força - a de trazer à linguagem aspetos da realidade não contemplados por uma razão instrumental e técnica e, dessa forma, fornecer bons argumentos para as teorias feministas.

Tal ponto de vista aproxima-me mais da defesa que Fraser e Nicholson fazem da possibilidade e mesmo da vantagem da relação entre feminismo e pós-modernidade. Na verdade, como elas, penso que os feminismos de qualquer latitude têm necessidade de libertar a racionalidade da rigidez e do totalitarismo, herdados do mundo moderno, para possibilitar que ela se transforme num recurso de discernimento e intervenção quer no plano teórico restrito, no sentido da constituição de uma produção científica ligada à complexidade da realidade, quer no campo mais alargado da compreensão da vida e do viver, no quadro da definição de novos modos de ser e de habitar que tornem sustentável as interações humanas e a ocupação do cosmos.

Todavia, a posição de Butler é muito desafiadora e leva-me a cavar mais fundo neste debate e procurar pensar de que modo a opressão e a discriminação assentam numa injustiça cognitiva que importa compreender, pondo em evidência que os paradigmas epistemológicos não são todos iguais, podendo ser responsáveis por mundividências libertadoras ou discriminadoras. Tendo em conta esta perspetiva, de que na base das desigualdades sociais existe uma injustiça cognitiva, penso que encontrar uma epistemologia da racionalidade que sirva um outro paradigma de abordagem do saber e do agir é tão fundamental para os Women's Studies como ressignificar o nosso passado, resgatando o papel que as mulheres tiveram nele. Isto é, penso que a investigação feminista necessita de uma conceção aberta sobre a racionalidade para se desenvolver sem ficar acantonada a um gueto ou a uma simples marginalidade sem consequências directas no saber em geral, para fugir daquilo que Virgínia Ferreira chama "o acantonamento das especialistas 
sobre as mulheres 'nas coisas das mulheres' que conduz à negação da relevância do seu trabalho para o saber da disciplina" (20).

Provavelmente, no universo de língua inglesa ou mesmo francesa, já há algum entrosamento entre as investigações feministas e a investigação em geral; todavia, no mundo de língua portuguesa, há um alheamento tão grande, das investigações feministas e da sua amplitude, quer a nível académico quer a nível da sociedade em geral $^{6}$, que, no meu entender, se torna tão imprescindível resgatar novas narrativas do passado que destaquem o papel das mulheres, como pugnar por um debate epistemológico que ponha a claro o que serve e o que não serve na construção de um saber mais justo e de um viver colectivo mais igualitário. No quadro desta análise, gostaria de convocar um texto de Boaventura de Sousa Santos, no qual designa o Pensamento Moderno Ocidental, como "pensamento abissal", para chamar a atenção para o seu carácter radicalmente dicotómico e excludente, fazendo uma crítica devastadora da perspetiva epistemológica da modernidade. Segundo o autor, tal modo de pensar caracteriza-se pelas distinções e pelas divisões, umas visíveis e outras invisíveis, mas que são fundamento das primeiras e marcam dois universos discursivos irredutíveis, incomensuráveis e repelindo-se mutuamente: "deste lado da linha" e "do outro lado da linha”. Diz ele:

A divisão é tal que "o outro lado da linha" desaparece enquanto realidade, torna-se inexistente, e é mesmo produzido como inexistente. Inexistência significa não existir sob qualquer forma de ser relevante ou compreensível. Tudo aquilo que é produzido como inexistente é excluído de forma radical porque permanece

\footnotetext{
${ }^{6}$ Penso que o exemplo mais flagrante da posição da nossa sociedade sobre isto é a designação de "violência doméstica", para descrever a situação de opressão e discriminação que as mulheres ainda sofrem entre nós.
} 
exterior ao universo que a própria concepção aceite de inclusão considera como sendo o Outro. A característica fundamental do pensamento abissal é a impossibilidade da co-presença dos dois lados da linha. Este lado da linha só prevalece na medida em que esgota o campo da realidade relevante. Para além dela há apenas inexistência, invisibilidade e ausência não-dialéctica. (3-4)

Ou seja, para este paradigma epistemológico, o que está em causa é a afirmação de um universal que se designa a si mesmo como abrangente, mas que não passa de um pseudouniversal, uma vez que é definido no âmbito de um "nós” que exclui os "outros", considerando-os inferiores e irrelevantes. Trata-se, portanto, neste texto, de desmontar um paradigma epistemológico que foi consentâneo com todas as formas de opressão e de colonialismo, real e simbólico. Embora Sousa Santos considere que a sua perspetiva pertence a uma "ecologia dos saberes", provavelmente, quer a sua análise quer a sua proposta poderiam ser classificáveis, por um olhar desconstrutor radical, como ainda relevando do "pensamento metafísico", pelo que, no meu ponto de vista, vale a pena fugir aos rótulos e aos slogans - sempre depreciativos e, também, sempre redutores - e ir desbravando caminhos de denúncia de todas as "formas cognitivas" que subtendem modos de saber e formas organizacionais discriminadoras. E ao nível dessas formas, convém radicalizar a desconstrução e analisar sempre de que modo elas estão ligadas a estruturas racionais de poder e poderão ter ressonâncias de exclusão. Assim sendo, penso que talvez valha a pena fazer uma breve passagem por aquilo que se poderia designar "da crítica da razão à crise da razão", para se compreender que não poderemos abandonar nem a modernidade, nem a pós-modernidade porque vivemos a condenação de pertencer a ambas.

Numa nota ao prefácio da $1 .^{\text {a }}$ edição da Crítica da Razão Pura, Kant dizia que o seu século era "o século da crítica”, ou seja, o século 
onde a razão, soberana, se reconhecia a si mesma a capacidade de se submeter a um livre e público exame que instaurasse, claramente, o seu poder e os seus limites. O iluminismo representava, assim, o Kairos da crítica da razão, o seu momento por antonomásia e, simultaneamente, revelava a imensa confiança na razão. Contudo, a herança da crítica da razão foi uma razão em crise, posta em questão por todas as hermenêuticas da suspeita - desde as clássicas de Marx, de Nietzsche e de Freud às feministas. Noutra perspetiva de análise, a racionalidade iluminista foi também duramente criticada pela Escola de Frankfurt - querendo pensar a sociedade democrática depois do fracasso da racionalidade posto a nu pela segunda grande guerra - através de Adorno e Horkheimer e mesmo de Habermas, que submeteram a racionalidade ocidental moderna a uma crítica feroz, denunciando o seu fundo de totalitarismo com o duplo efeito perverso de uma certa usura sobre o mundo natural e de uma ação de exclusão em relação a tudo que não pudesse encaixar-se nos padrões tecnológicos e instrumentais.

Estas perspetivas põem, então, em evidência que a razão forte que fundou a sociedade moderna é também uma razão opressora, articulada com o exercício da violência, da dominação e da exclusão (cf. Adorno e Horkheimer). Dito de outra forma, parece que a capacidade clarificadora e discriminadora da razão iluminista, por um lado, e a confiança na sua possibilidade de transformar o mundo, por outro, não foram suficientes para a construção de um saber e de um viver verdadeiramente igualitários, tendo sido isso que as diferentes críticas sob o rótulo de "pós-modernas" puseram a claro, denunciando a pertença da razão moderna a um paradigma discriminador. Se se quiser atender às palavras de Butler e ter em atenção a diversidade do chamado "pós-modernismo", ter-se-á de tomar a relação entre "pós" e "modernismo" como uma relação complexa, nomeadamente, chegar ao reconhecimento de que o "pós" aponta para a ideia de descentralização e de deslocação, ou seja, 
para a ideia de um estilhaçar do centro. Nesse contexto, teremos, porventura, de tomar consciência de que cada pessoa ocupa apenas uma posição entre muitas outras, e, por isso, teremos de aceitar as diferenças como um valor. Em alguns pensadores, como Vattimo, isso significa a derrota da arrogância da razão totalitária e imperialista, potenciando a configuração de uma racionalidade mais aberta e integradora:

Se, afinal, falo o meu dialeto num mundo de dialetos, estarei também consciente de que ele não é a única língua, mas antes um dialeto entre muitos outros. Se professo o meu sistema de valores - religiosos, estéticos, políticos, étnicos - neste mundo de culturas plurais, terei também uma consciência aguda da historicidade, contingência, limitação de todos estes sistemas, começando pelo meu. (1994: 17-18)

Não se trata, pois, de relativismos fáceis, mas sim de compreendermos que "vivemos num mundo interpretado" e que cada interpretação é sempre parcelar e unilateral, o que significa que talvez a pós-modernidade seja coalescente com a promessa de um renascimento do próprio pensar que escute e respeite a realidade na sua profundidade abissal e na sua diversidade complexa e que, com esse novo modo de pensar, encontremos "um novo modo de ser (talvez, por fim) humanos" (idem: 19).

Por outro lado, se a razão toda-poderosa não serviu nem a causa das mulheres, nem a do cosmos, mas, pelo contrário, numa lógica totalizadora, calculista e segregadora, classificou e explorou, excluindo dos quadros canónicos e do direito de cidadania epistémica tudo o que não se adequava à sua força unificadora, então, talvez se deva fazer uma exploração mais fina dos sentidos que podem ser extraídos de uma razão em crise ou de uma razão débil, de maneira que se possa configurar um conceito de racionalidade que, por um lado, 
rememore o poder discriminador da razão moderna e, por outro, se abra a novas formas de entendimento e compreensão da realidade. Uma racionalidade que reconheça que o nosso conhecimento assenta em condicionamentos inerentes a sermos humanos: a nossa inserção histórica, social, e cultural e o facto de termos um corpo fazem do discurso humano, qualquer que ele seja, uma interpretação mais ou menos validada pelas premissas e axiomas em que se inscreve. Nesse sentido, embora no contexto da dimensão provisória apontada por Butler, talvez se pudessem definir três parâmetros essenciais na definição dessa racionalidade:

Demarcar-se do padrão epistemológico ocidental que instaurou as ideias de neutralidade, universalidade e objetividade como bandeiras da verdade e do valor do saber, assentes na ideia de uma razão pura, transparente e assética que produzisse e fornecesse um conhecimento sem impressão digital.

Não abandonar a intencionalidade universal, mas saber recusar a universalidade abstracta do iluminismo, procurando uma universalidade assimptótica, que marca uma direcção, um horizonte regulador.

Finalmente, fazer entrar no campo do saber o valor da argumentação, contribuindo para a criação de uma "cultura de razões" e para a defesa da necessidade de se procurarem diferentes lugares de explicação e de compreensão da realidade.

\section{Obras citadas}

Adorno, T.A. \& M. Horkheimer. Trad. Éliane Kaufholz. La Dialectique de la raison. Paris: Gallimard, 1974. Print.

Amorós, Celia. Tiempo de Feminismo. Madrid: Cátedra, 1997. Print.

Anderson, Perry. Les orígines de la posmodernidad. Trad. Luis Andrés Bredlow. Barcelona: Anagrama, 2000. Print.

Butler, J. "Fundamentos contingentes: O feminismo e a questão do "pós-modernismo". Trad. Pedro Maia Soares. Cadernos Pagu 11 (1998):11-42. Print. 
Bauman, Zygmunt. Modernity and Ambivalence. Ithaca, NY.: Cornell University Press, 1991. Print.

Calinescu, Matei. Cinco caras de la modernidad. Madrid: Tecnos, 1991. Print.

Connor S., ed. The Cambridge Companion to Postmodernism. Cambridge: Cambridge University Press, 2004. Print.

Ferreira, Virgínia. "Estudos sobre as mulheres em Portugal: a construção de um novo campo científico". ex aequo 5 (2001): 9-27. Print.

Fraser, Nancy \& Linda Nicholson. "Critica social un encuentro entre el feminismo y el posmodernismo”. Trad. Márgara Averbach. Org. L. Nicholson. Feminismo/ Posmodernismo. Buenos Aires: Feminaria, 1992. 7-30. Print.

Habermas, J. Pensamento pós-metafísico: Estudos filosóficos. Trad. Flávio Beno Siebeneichler. Rio de Janeiro: Tempo brasileiro, 1990. Print.

Harvey, David. Condição pós-moderna. Trad. Adail Ubirajara Sobral. São Paulo: Edições Loyola, 1992. Print.

Henriques, Fernanda. "Elisabeth Badinter: Racionalismo, igualdade e feminismo". Org. AAVV. O longo caminho das mulheres: feminismos 80 anos depois. Lisboa: Dom Quixote, 2007. 245-254. Print.

Lyotard, J-F. La condition postmoderne: rapport sur le savoir. Paris: Minuit, 1979. Print.

Molina Petit, Cristina. "Lo femenino como metáfora en la racionalidad postmoderna y su (escasa) utilidad para a Teoría Feminista”. Isegoría 5 (1992): 129-143. Print.

—. Dialéctica feminista de la ilustración. Barcelona: Anthropos, 1994. Print.

Sousa Santos, Boaventura. "Para além do pensamento abissal: Das linhas globais a uma ecologia de saberes". Revista Crítica de Ciências Sociais 78 (2007): 3-46. Print.

Vattimo, Gianni. As aventuras da diferença: O que significa pensar depois de Heidegger e Nietzsche. Trad. José Eduardo Rodil. Lisboa: Edições 70, 1988. Print.

_. "Posmodernidad: una sociedad transparente?". AAVV. En torno a la posmodernidad. Barcelona: Anthropos, 1994. 9-19. Print. 